\title{
Needs and skills of informal caregivers to care for a dependent person: a cross- sectional study
}

\author{
Maria dos Anjos Coelho Rodrigues Dixe ${ }^{1,2^{*}}$ (D), Liliana Fernanda da Conceição Teixeira ${ }^{1,2}$, \\ Timóteo João Teixeira Camacho Coelho Areosa', Roberta Caçador Frontini ${ }^{1}$, Teresa de Jesus Almeida Peralta ${ }^{1,3}$ and \\ Ana Isabel Fernandes Querido ${ }^{1}$
}

\begin{abstract}
Background: The world is facing many socio-demographic changes, such as an increased average life expectancy and the presence of chronic and non-communicable diseases, which in turn, leads to an enhanced dependency on others. Consequently, the demand for informal caregivers has significantly increased during the past few years. Caring for a dependent person is linked to a series of burdens that often leads to physical, psychological and emotional difficulties. Taking into consideration the difficulties faced by informal caregivers, knowing in which areas of functioning they need more guidance may help to relieve their burden. Therefore, the main goal of this study is to better understand the needs and competencies of the informal caregiver when caring for a dependent person in the different self-care domains.
\end{abstract}

Methods: This cross-sectional study used a questionnaire administered on a single occasion by face-to-face interview. Descriptive and inferential statistics alongside non-parametric statistical techniques such as the MannWhitney test and Spearman's correlation were used.

Results: The average age of the 143 informal caregivers is 58 years old, with the youngest in our sample being 21 years of age. Most of them are female, and $50 \%$ of them are children taking care of one of their parents. Most of the dependent people are completely dependent in the areas of comfort and hygiene (53.8\%) and medication management (55.9\%). The female informal caregivers see themselves as having more competencies in sanitary hygiene than the male ones, with no significant differences in their competencies' perception in the other areas of self-care. Older caregivers see themselves as less competent in certain areas of self-care such as feeding, mobility, transfers, medication and symptoms management and communication. Most of the information given to the informal caregiver is about the disease (82.3\%) and the medication management (80.4\%). There are still a lot of areas of self-care, where no information, or almost none, is given to the informal caregivers.

Conclusions: Before home discharge of a dependent person, it is important to acknowledge the needs and competencies of the informal caregiver, to capacitate them in looking after their relatives, to help decrease their burden and consequently, decrease the number of hospital readmissions.

Keywords: Dependent person, Informal caregiver, Caregiver needs, Caregiver competencies

\footnotetext{
* Correspondence: maria.dixe@ipleiria.pt

${ }^{1}$ Center for Innovative Care and Health Technology, Escola Superior de

Saúde do instituto Politécnico de Leiria, Campus 2 - Morro do Lena, Alto do

Vieiro - Apartado 4137, 2411-901 Leiria, Portugal

${ }^{2}$ Escola Superior de Saúde do instituto Politécnico de Leiria, Campus 2 -

Morro do Lena, Alto do Vieiro - Apartado 4137, 2411-901 Leiria, Portugal

Full list of author information is available at the end of the article
}

(c) The Author(s). 2019 Open Access This article is distributed under the terms of the Creative Commons Attribution 4.0 International License (http://creativecommons.org/licenses/by/4.0/), which permits unrestricted use, distribution, and reproduction in any medium, provided you give appropriate credit to the original author(s) and the source, provide a link to the Creative Commons license, and indicate if changes were made. The Creative Commons Public Domain Dedication waiver (http://creativecommons.org/publicdomain/zero/1.0/) applies to the data made available in this article, unless otherwise stated. 


\section{Background}

The world's population is increasingly ageing in nearly every country in the world, including Portugal [1]. There has been an increase both in the average life expectancy of the population [1-3] and in the presence of chronic and non-communicable diseases [3] which is linked to the person's survival and, often, to the presence of morbidity and dependence on others [4]. Moreover, people tend to prefer to live at home as long as possible [5]. Nonetheless, dependency cases are related to healthcare recurrences. Taking the information above into account, it is expected that the need for informal caregivers will increase in the next few years [5].

The informal caregiver usually has different responsibilities [6], providing unpaid assistance to a dependent person and performing daily life tasks concomitantly with other activities related to the healthcare of the person [7], usually related with medication, wound treatment and equipment monitoring [8]. Informal caregivers are usually family members or close relatives $[9,10]$ providing partial or full care to a dependent person with difficulties in self-care, facilitating their well-being and helping in different tasks and activities [11].

According to Orem [12], there are some universal self-care requirements that should be important areas of evaluation in a dependent person: 1) the maintenance of sufficient amount of air; 2) sufficient intake of water; 3) sufficient intake of food; 4) care regarding elimination processes; 5) balance between activity and rest; 6) balance between solitude and social interaction; 7) prevention of hazards to human life, the functioning, and well-being of the human being; and 8) promotion of the functioning and development of the human being within the social groups. Nonetheless, family caregivers usually report insufficient preparation for an adequate continuity of care to the dependent person on their return home [13, 14].

Moreover, and although research has found contradictory findings [15], a large percentage of studies found that caring for a dependent person is related to a series of burdens that often takes them to their physical, psychological and emotional limits [15-17], impacting the whole family system [15]. The responsibilities imposed by the caregiving situation may interrupt social life, activities or even work, which may be challenging [18]. For instance, some studies report that caregiving is usually associated with a deterioration in the quality of life $[5,6$, $19,20]$, higher levels of depression symptoms $[5,19,21$, 22], greater financial burden $[19,23,24]$ and greater physical impairment $[19,25]$ especially when compared to non-carers. Therefore, caregiver burden is frequently defined as the emotional, social and financial stress imposed by the illnesses of the dependent person onto the caregiver [23, 26]. Nevertheless, informal caregivers experience challenging issues related not only to the condition of the dependent person, but also to their emotional feelings [11]. Some studies tried to better understand the reasons behind the experience of difficulties in caregivers. Pinquart and Sörensen [19], for example, explained that higher levels of psychological distress among spouses may be explained by higher levels of care provision. The caregiver burden has also been related to their own psychological distress and quality of life [26, 27].

Informal caregivers are usually aware of the difficulties they may face after the dependent person's hospitalisation. They usually report the need for information regarding various areas of functioning, such as information regarding monitoring, management, personal care delivery, care skills, and handling emotional distress [28].

Because caregivers represent an essential part of the care network, it is important to support caregivers in managing their difficulties in caregiving $[11,29]$. The quality of care provided by an informal caregiver depends on the quality of life and well-being of the caregiver itself. Moreover, and although literature refers to difficulties in caregiving, it is also acknowledged that even facing similar situations, caregivers may experience different levels of burden and/ or different levels of subjective well-being [5]. It is thus of utmost importance to understand the resources these caregivers use (or will need) to minimise the physical and emotional burden they may face, which could be linked to the care provided. Health professionals may use this information to provide better care plans, enhancing supportive measures and thus, lead to more successful care conditions. Health care professionals have a set of instruments and information that might meet the specific needs of each dependent person. Consequently, promoting the well-being of caregivers and provide them with useful information should be among the main concerns of health professionals $[16,28]$, especially taking into account that providing support for caregivers may not be enough [15].

Besides, some of the problems faced by the caregiver at home are the major causes of readmission of the dependent person at the hospital [28]. Thus, understanding the major difficulties that the caregivers face during the provision of care is fundamental for any healthcare professional aiming to better help the caregivers to provide effective health care, which consequently may help to significantly reduce the unnecessary use of hospital services. Furthermore, and taking into consideration the difficulties faced by caregivers, knowing in which areas of functioning they need more guidance may help relieve the burden of the caregiver and, consequently, help to improve their health. Although the impact of caregiving on a dependent person has begun to be explored more extensively, there is still a lack of research regarding the specific needs and skills regarding 
a dependent person's self-care. To our knowledge, there have been few studies assessing those variables all together in several areas of functioning.

Therefore, the main objectives of this study is to better understand the needs and skills of the informal caregivers of a dependent person in self-care in various areas of functioning, namely: feeding; sanitary hygiene; comfort; mobility; movement; dress and undress; medication; symptoms management and communication, to identify the degree of dependency of the dependent person; to identify the information given to the informal caregivers and to relate the skills for caring for a dependent person in self-care with gender, age and previous caregiver experience.

\section{Methods}

\section{Study design}

This study is reported in line with the STROBE statement [a]. This is a cross-sectional study carried out using face-to-face quantitative structured interviews based on standardized questionnaires.

\section{Participants and setting}

The target population of this study was made up of informal family caregivers of dependent people (assessed by health care professionals using the Barthel Index) in at least one of the self-care categories and who were discharged from the medical units at a Portuguese urban hospital to their home, no matter their age, diagnosis and dependency.

The selection of caregivers was carried out by health care professionals.

Caregiver's interviews were performed by nurses and nursing students who did not work at the unit to prevent influencing patients' answers, following a standardised protocol.

All the interviews were carried out at the hospital at the moment of discharge home.

Participants were given information about the study and that they were free to withdraw from the study at any time for any reason, and with no obligation to give the reason for withdrawal.

The names and any other identifying details of participants were not collected in any of the surveys.

Data collection occurred from February to June 2017. In this period 900 patients were discharged from hospital, but only 324 filled in the eligibility criteria for this study. From those, 143 informal caregivers accepted to participate, representing $44,1 \%$ of caregivers of dependent people discharged home.

\section{Measures}

The interview conducted consisted of two parts:

a) Socio-demographic and family data, the experience of the caregiver, b) Caregiver's skills specifically relating to care, professional information receive which provided them with information.

The items used to assess the caregiver's skills in caring for a dependent person were built based on four criteria: a) the items of other instruments, b) meetings with health care professionals, c) meetings with informal caregivers, d) bibliographical research.

Given these criteria, the first version of the instrument was made up of 114 items spread over 9 domains corresponding to the areas of skills. These items have been subject to evaluation by a panel of experts using the Delphi Method. Each of these items was rated on 5 response options: Strongly Disagree; Disagree; Agree; Strongly Agree and Not applicable. For each of the areas and respective items, the informal caregiver was asked about the degree of dependence of their family member using a close-ended question with three response options: Independent, partially dependent and totally dependent.

For this study, it was pretended to access the perception of informal caregivers on the dependency of their family member. For this reason, and considering that the Barthel Index, designed to health care professionals, could not address all the issues of dependency that worries the caregivers, we decided on to create a new instrument. By using the items that caregivers referred to be relevant for their caring role, together with specific items pointed out by health care professionals, the instrument at its final version, covers different and specific areas, and it is broader than the existing instruments to measure Activities Daily Living (ADL) and Instrumental Activities of Daily Living (IADL).

After determining the internal consistency of each of the domains, the scale was composed of 101 items according to the data in Table 1 . The 13 deleted items were based on two criteria: alpha of each indicator was not higher than the global alpha of their respective domains, and the results of the correlation of each item with the global rating (by removing the respective item) were not higher than 0.20. An Exploratory factor analysis was conducted and described in the analysis.

The factor analysis determined that 101 items were organized in the predefined domains (Additional file 1).

It should be noted that all of the domains have good reliability, except for communication domain which presents a Cronbach's Alpha score lower than recommended $(<0.60)$. However, we have not excluded it due to its value in this area of caregivers' skills.

\section{Ethical approval}

The study protocol, the participant informed consent documentation were submitted to the Central Hospital 
Table 1 Number of items in each subscale and Cronbach's alpha value of each subscale

\begin{tabular}{llll}
\hline & $\begin{array}{l}N^{\circ} \text { items before } \\
\text { validation }\end{array}$ & $\begin{array}{l}\mathrm{N}^{\circ} \text { end } \\
\text { items }\end{array}$ & $\begin{array}{l}\text { Cronbach's } \\
\text { alpha }\end{array}$ \\
\hline Feeding & 24 & 19 & 0.905 \\
Sanitary hygiene & 13 & 10 & 0.787 \\
Comfort & 14 & 12 & 0.904 \\
Mobility & 12 & 12 & 0.835 \\
Transfer & 10 & 10 & 0.859 \\
Dressing and undressing & 7 & 6 & 0.685 \\
Medication & 12 & 10 & 0.808 \\
Management of symptoms & 17 & 17 & 0.911 \\
Communication & 5 & 5 & 0.544 \\
Total items & 114 & 101 & \\
\hline
\end{tabular}

of Leiria Ethics Committee (04-2017/05/02), who approved the study.

An appropriate location for data collection was always ensured, and the norms in use the Declaration of Helsinki (2014) were met.

\section{Analysis}

Descriptive and inferential statistics were used. Taking into account the size of the sample, subsamples, and very different sample sizes, non-parametric statistical techniques were used, namely the Mann-Whitney test, Spearman's correlation according to the type of variables under study.

The reliability of the 9 domains was measured by calculating internal consistency (Cronbach's alpha), and individual item analysis was performed by calculating the corrected item-total correlations and $\alpha$ if the item was removed.

In this study means of Cronbach's $\alpha>0.6$ are considered acceptable, $\alpha>0.7$ considered good, $\alpha>0.8$ very good and $\alpha>0.9$ are considered excellent.

Exploratory factor analysis was conducted with the 101items. Using Varimax rotation, and Kaiser's eigenvalues greater than one, a nine-factor structure was extracted, explaining $61.039 \%$ of the variance. All the items correlated at least 0.3 with at least one other item, non-inclusion of items that scored in more than one factor less than 0,10 and not considering each factor with less than three items, suggested reasonable factorability. The Kaiser-Meyer-Olkin measure of 0.745 , above the recommended value of 0.6 was considered good, and Bartlett's test of sphericity (16, $171.631 ; p=0.000)$ indicated a good fit of the structure. The diagonals of the anti-image correlation matrix were also all over 0.5 Finally, the communalities were all above 0.392 and below 0.817, further confirming that each item shared some common variance with other items. Given these overall indicators, factor analysis was deemed to be suitable.

It should be noted that all of the domains have good reliability, with the exception of communication domain which presents a Cronbach's Alpha score lower than recommended $(<.60)$.

\section{Results}

a) Characterisation of the sample regarding sociodemographic characteristics, professional situation and previous experience as an informal caregiver

The 143 participating caregivers had an average of $58.7 \pm 15.4$ years, the youngest being 21 years old and the eldest 88 years old. $67.8 \%$ of the caregivers lives with the patient in the same household, and $90.2 \%$ had already cared for them previously, with $75.4 \%$ having help from another person to help them care for the patient. In the area of education and training, 38.5\% of the caregivers completed primary school education, $16.8 \%$ completed their compulsory high school education, $14.7 \%$ have completed sixth form education, $11.9 \%$ of the sample had completed middle school education, $11.9 \%$ had completed higher education, and $6.3 \%$ had no formal education.

Of the $90.2 \%$ of caregivers who had previously cared for the dependent person, they did so on average on $89.1 \pm 50.9$ of days. The caregivers were predominantly female $(116,81.1 \%)$ and regarding their relationship to the patient, $50.3 \%$ were their child, $35.7 \%$ were their spouse, $2.1 \%$ were siblings, $2.1 \%$ were grandchildren or others $(9.8 \%)$.

These caregivers did not care for more than one dependent person and $75.4 \%$ have help from another person to care for their dependent relative.

\section{a) Level of dependence of the dependent person perceived by the caregiver}

These caregivers take care of 143 dependent people in at least one of the self-care activities. The average age of the $51.7 \%$ (74) female patients and the $48.3 \%$ (69) male patients is $80.7 \pm 10.1$ years.

By analysing Table 2, it can be seen that, in terms of self-care, the majority of people are totally dependent on comfort, and medication self-care, and that they are less dependent in terms of feeding and mobility self-care, $5.7 \%$ (8) people were discharged to their homes with a nasogastric tube, and the same was observed for the presence of urinary catheter.

b) Ability of the informal caregiver to take care of the dependent person in their self-care needs 
Table 2 Distribution of the sample's responses about the degree of dependence of the dependent person and presence of equipment

\begin{tabular}{|c|c|c|c|c|c|c|}
\hline \multirow[t]{2}{*}{ Self-care } & \multicolumn{2}{|c|}{ Independent } & \multicolumn{2}{|c|}{ Partially dependent } & \multicolumn{2}{|c|}{ Totally dependent } \\
\hline & $\mathrm{N}^{\circ}$ & $\%$ & $\mathrm{~N}^{\circ}$ & $\%$ & $\mathrm{~N}^{0}$ & $\%$ \\
\hline Feeding & 10 & 7.0 & 84 & 59.2 & 48 & 33.8 \\
\hline Sanitary hygiene & 10 & 7.0 & 71 & 49.7 & 62 & 43.4 \\
\hline Comfort & 3 & 2.1 & 63 & 44.1 & 77 & 53.8 \\
\hline Mobility & 12 & 8.4 & 74 & 51.4 & 57 & 39.9 \\
\hline Transfer & 24 & 16.8 & 62 & 43.4 & 57 & 39.9 \\
\hline Dressing and undressing & 12 & 8.4 & 66 & 46.2 & 65 & 45.5 \\
\hline Management of medication & 8 & 5.6 & 55 & 38.5 & 80 & 55.9 \\
\hline Management of symptoms & 22 & 15.4 & 55 & 38.5 & 66 & 46.2 \\
\hline
\end{tabular}

When comparing the various values found, we confirm that, regarding management of symptoms and mobility, the caregiver, both male and female, had a lower level of agreement in the assessment of their skills to take care of their family member. It is important to note that the differences found between the skills of the male and female caregivers do not demonstrate a statistical significance except for the area of sanitary hygiene self-care (Table 3) and women self-assessed themselves as more capable than men.

As caregivers become older, they perceived themselves as less capable to provide care in the following domains of self-care: feeding ( $\mathrm{rs}=-.241 ; p=.004)$; mobility ( $\mathrm{rs}=-.210$; $p=.012)$; transfer ( $\mathrm{rs}=-.169 ; p=.044)$; medication ( $\mathrm{rs}=$ $-.279 ; .001) ; \quad$ management of symptoms $(\mathrm{rs}=-.370$; $p=.000)$; communication ( $\mathrm{rs}=-.288 ; \mathrm{p}=.000)$. The fact that they have previously been caregivers did not provide them with greater capability to take care of their family member, with the exception of the area of the self-care concerning management of medication $(\mathrm{U}=364.000 ; p>0.01)$.

c) Information received by the caregiver to assist the dependent person in their self-care
Regarding the required information given to caregivers to help them in the self-care, we found that the percentage is higher in information given about the illness suffered $(82.3 \%)$ and in the self-care of management of medication (80.4\%). Importantly, a large percentage $(32.9 \%)$ of caregivers did not receive any information concerning the selfcare areas of bathing, followed by the self-care area of getting ready and get dressed (26.6\%) and toilet use (26.4\%). Also noteworthy is the higher percentage (Table 4) of the caregivers who did not receive information about the financial support (39.9\%) and auxiliary equipment (28.0\%).

Regarding the source of the information the caregiver has to help in the self-care of the dependent person, among the valid responses, we have found that nurses are the professional staff who give most information to the caregiver, except for information about the disease where the main professional providing information is the doctor. It should be noted that other caregivers were indicated as sources of information for all self-care areas particularly on community services (Table 5).

\section{Discussion}

This study aimed to investigate the needs and skills of informal caregivers in caring for a dependent person in

Table 3 Results of the application of the Mann-Whitney $U$ test on the skills of caregivers depending on the sex of the caregiver

\begin{tabular}{|c|c|c|c|c|c|c|c|c|}
\hline & \multicolumn{3}{|c|}{ Women $(n=116)$} & \multicolumn{3}{|c|}{ Men $(n=27)$} & \multirow[t]{2}{*}{$U$} & \multirow[t]{2}{*}{$p$} \\
\hline & median & Mean & SD & median & Mean & SD & & \\
\hline Feeding & 3.15 & 3.16 & .386 & 3.15 & 3.10 & .345 & 1448.000 & .543 \\
\hline Sanitary hygiene & 3.27 & 3.24 & .331 & 3.22 & 3.12 & .275 & 1170.500 & .041 \\
\hline Comfort & 3.55 & 3.47 & .406 & 3.45 & 3.36 & .367 & 1247.000 & .100 \\
\hline Mobility & 2.88 & 2.87 & .416 & 2.88 & 2.90 & .305 & 1536.000 & .877 \\
\hline Transfer & 3.03 & 3.05 & .401 & 3.03 & 2.98 & .268 & 1340.000 & .242 \\
\hline Dressing and undressing & 3.34 & 3.36 & .405 & 3.35 & 3.33 & .350 & 1481.000 & .661 \\
\hline Medication & 3.30 & 3.26 & .401 & 3.25 & 3.22 & .374 & 1474.000 & .634 \\
\hline Management of symptoms & 2.83 & 2.81 & .479 & 2.81 & 2.82 & .447 & 1558.500 & .969 \\
\hline Communication & 3.00 & 2.92 & .358 & 2.93 & 3.00 & .471 & 1477.500 & .643 \\
\hline
\end{tabular}


Table 4 Distribution of responses by the informal caregivers regarding the necessary information they received to support self-care

\begin{tabular}{|c|c|c|c|c|c|c|c|c|}
\hline \multirow[t]{2}{*}{ Information about } & \multicolumn{2}{|c|}{ Necessary information } & \multicolumn{2}{|c|}{ Not enough information } & \multicolumn{2}{|c|}{ None } & \multicolumn{2}{|c|}{ Not applicable } \\
\hline & $\mathrm{N}^{\circ}$ & $\%$ & $\mathrm{~N}^{\circ}$ & $\%$ & $\mathrm{~N}^{\circ}$ & $\%$ & $\mathrm{~N}^{0}$ & $\%$ \\
\hline Illness & 117 & 81.8 & 23 & 16.1 & 3 & 2.1 & & \\
\hline Self-care bathing & 77 & 53.8 & 17 & 11.9 & 47 & 32.9 & 2 & 1.4 \\
\hline Self-care get ready and get dressed & 64 & 44.8 & 26 & 18.2 & 38 & 26.6 & 15 & 10.5 \\
\hline Self-care feeding & 64 & 44.8 & 15 & 10.5 & 34 & 23.8 & 30 & 21 \\
\hline Self-care toilet use & 58 & 45.0 & 8 & 6.2 & 34 & 26.4 & 29 & 22.5 \\
\hline Self-care transfer & 59 & 41.3 & 20 & 14.0 & 33 & 23.1 & 31 & 21.7 \\
\hline Self-care mobility & 58 & 40.6 & 38 & 26.6 & 34 & 23.8 & 13 & 9.1 \\
\hline Self-care taking medication & 115 & 80.4 & 17 & 11.9 & 1 & .7 & 10 & 7.0 \\
\hline Auxiliary equipment & 39 & 27.3 & 35 & 24.5 & 40 & 28.0 & 29 & 20.3 \\
\hline Community services & 59 & 41.3 & 24 & 16.8 & 40 & 28.0 & 20 & 14.0 \\
\hline Financial support & 31 & 21.7 & 17 & 11.9 & 57 & 39.9 & 38 & 26.6 \\
\hline
\end{tabular}

self-care. The 143 informal caregivers are family members related to the patient $[9,10]$ had an average age of 58.7 years, which indicates an adult sample of working age. It is important to note that a large portion of the sample is made up of informal caregivers who are also elderly, which suggests that the ageing of the population increases the number of elderly caregivers.

As was observed in the sample, the caregivers tend to be elderly, which limits their ability to care for the dependent person, demonstrating the vulnerability inherent in the age of the caregiver in carrying out many of their tasks [30].

The previous care experience does not prove increased effectiveness in caring for the dependent person. We can observe in the results, which reveal that caregivers with previous experience have difficulties in some areas. The pre-existing difficulties, often associated to the low level of education and the high level of complexity of the problems suffered by the dependent person, result in high levels of anxiety and insecurity for the caregiver, which leads to them being afraid of performing some tasks [30, 31]. In this regard, the tasks which require manual dexterity and technique to carry them out, such as well as hygiene tasks (bed bathing), transfers and mobility, medication and feeding through a tube, and tracheal aspiration have caused great concern in the caregiver [30]. Data which are similar to those presented in this study, to the extent that a large portion of the caregivers states that these aspects are one of the critical points and create greater difficulty in caring for the dependent person. Therefore, the caregivers tend to develop multiple strategies to simplify them, not taking into consideration the criteria for the implementation of the task or its degree of complexity, which could have implications for the health of the person they care for and for the caregiver $[26,30]$.
On the other hand, and according to the data presented, it has been observed that there are statistical differences between caregivers who are spouses and caregivers who are children, because the spouses tend to have a smaller support network and to request less informal support [19]. In line with the literature, our findings confirm that caregivers acquire formal information mostly through the health care team, particularly the nursing staff, as they have more and closer contact when compared with other professionals $[19,32]$. Despite receiving information, this is not enough for a large majority of caregivers as observed in other studies $[13,14]$.

In recent years, especially in European countries, there has been a prevailing feeling for a need to intervene with the informal caregiver using an interdisciplinary team, especially in people with certain diseases including Alzheimer's disease and other dementia types, in order to reduce not only the burden carried by the informal caregiver but also to reduce existing barriers (on behalf of the Right Time Place Care Consortium et al) [33]. Therefore, health care professionals should enable informal caregivers, supporting and making small tasks easier, thus reducing their exhaustion and the incorrect measures taken by informal caregivers.

\section{Strengths and limitations}

Certain limitations of the study must be mentioned. First, most caregivers participating in the study had previous experience in caring for dependent people. Therefore, generalizability of our results is limited as the small percentage of caregivers for the first time might had influenced the data. Second, as a cross-sectional study, it was based on the survey results. Therefore, it has limitations in providing an explicit, causal inference which should be based on the temporal relationships among the variables. Third, the study did not consider the type of training interventions provided by nurses during 
Table 5 Distribution of responses by the informal caregivers regarding the information given to caregivers to support self-care ${ }^{a}$

\begin{tabular}{|c|c|c|c|c|c|c|c|c|c|c|}
\hline \multirow[t]{2}{*}{ Information on } & \multicolumn{2}{|c|}{ Doctor } & \multicolumn{2}{|c|}{ Nurse } & \multicolumn{2}{|c|}{ Doctor and nurse } & \multicolumn{2}{|c|}{ Nurse and caregiver } & \multicolumn{2}{|c|}{ Others Caregiver } \\
\hline & $\mathrm{N}^{\circ}$ & $\%$ & $\mathrm{~N}^{\circ}$ & $\%$ & $\mathrm{~N}^{0}$ & $\%$ & $\mathrm{~N}^{0}$ & $\%$ & $\mathrm{~N}^{\circ}$ & $\%$ \\
\hline Illness $(n=140)$ & 105 & 75.0 & 7 & 5.0 & 17 & 12.1 & 0 & 0.0 & 11 & 7.9 \\
\hline Self-care bathing $(n=94)$ & 5 & 5.3 & 33 & 35.1 & 2 & 2.1 & 51 & 54.3 & 3 & 3.2 \\
\hline Self-care get ready and get dressed $(n=89)$ & 7 & 7.9 & 28 & 31.5 & 1 & 1.1 & 50 & 56.2 & 3 & 3.4 \\
\hline Self-care feeding $(n=89)$ & 4 & 4.5 & 29 & 32.6 & 1 & 1.1 & 52 & 58.4 & 3 & 3.4 \\
\hline Self-care toilet use $(n=78)$ & 5 & 6.4 & 20 & 25.6 & 0 & 0 & 50 & 64.1 & 3 & 3.8 \\
\hline Self-care transfer $(n=78)$ & 2 & 2.6 & 22 & 28.2 & 2 & 2.6 & 49 & 62.8 & 3 & 3.8 \\
\hline Self-care mobility $(n=94)$ & 11 & 11.7 & 40 & 42.6 & 1 & 1.1 & 39 & 41.5 & 3 & 3.2 \\
\hline Self-care taking medication $(n=132)$ & 18 & 13.6 & 37 & 28.0 & 28 & 21.2 & 45 & 34.1 & 4 & 3.0 \\
\hline Auxiliary equipment $(n=77)$ & 10 & 13.0 & 25 & 32.5 & 0 & 0.0 & 36 & 46.8 & 6 & 7.8 \\
\hline Community services $(n=86)$ & 12 & 14.0 & 24 & 27.9 & 6 & 7.0 & 3 & 3.5 & 41 & 47.7 \\
\hline Financial support $(n=49)$ & 5 & 10.2 & 7 & 14.3 & 4 & 8.2 & 0 & 0.0 & 33 & 67.3 \\
\hline
\end{tabular}

${ }^{a}$ The ' $n$ ' corresponds to the number of caregivers who did not indicate 'not applicable'

internment and this should be recognized in interpreting our study results. Also, this study was based on the survey results. Therefore, the range of statistics was limited to the variables and their descriptions as presented in the survey and it does not explore the skills of caregivers living in rural areas compared to urban. Methodologically, the study lacks a power analysis for the sample size determination.

Nevertheless, this study was part of a larger project aiming to develop innovative solutions to help caregivers to care for their dependent relatives. This might explain the limited number of participants readmitted to the hospital during the study.

\section{Implications for practice and future research}

This study has several implications. The high rate of hospital readmissions and the use of Emergency Departments for non-urgent situations are related to an inadequate preparation of informal caregivers to care for their dependents at the time of discharge [34, 35]. This is a major problem facing health care system impacting in both organization and economics which should attract more attention from related health service managers and policy makers. Informal caregivers represent an important part of the health care provided to dependent people. Our study revealed a caregiver profile of working-aged adults. On the other hand, as caregivers grow older their ability to care for their relatives tends to decrease. Hence a new set of policy actions will be required to support caregivers in their caring role. It has been shown in this study that nurses are the preferred source of information. Nevertheless, the information received by caregivers was not enough to reinforce their ability to perform their caring tasks. We therefore suggest the implementation of a new different training model of caregivers in which the information provided cover the gaps identified in the present study and simultaneously empower the caregiver and users in all self-care domains. The use of several sources of information as well as the inclusion of information and communication technologies (ICT) would be considered as an upgrade of caregivers training, particularly the development digital materials (videos, website, app) addressing different caring tasks in several domains. Meanwhile, it's essential to improve communication between hospital and homecare so that caregivers could have a better support in the transition back home with a new dependency. Moreover, the schools of health sciences should focus on interdisciplinary collaboration among several health care students regarding the development of educational and training programs to empower caregivers.

This study has implications for nursing education, practice, and research. The identification of needs of caregivers, and the skills they need to care for their dependent relatives and the sources of information they use should be considered in nursing schools' curricula. Caregivers health literacy should be embedded in nursing programs and students should be trained to develop skills to educate and empower patient and caregiver. For nursing practice in the community, the results could serve as an inspiration for the needs to be attended inhome care nursing. Nurses in the community should be aware of the profile of the caregivers and develop new strategies of caregiver's education that include the sources of information preferred.

Longitudinal research is needed to characterise the needs and the ability of the caregivers to perform caretaking. Research should also be conducted in health career students and teachers regarding their perceptions about health literacy and the role of health care professionals in patients and caregivers' health literacy. 


\section{Conclusions}

This paper gives us an insight into the needs of the informal caregiver of a dependent adult. Informal caregivers are an important part of the care network, and therefore they require support in how to provide that care. The quality of the care provided depends not only on the caregiver well-being but also on the information/ handover of the care provided by the health care professional. Prior to home discharge of a dependent person, it is important to acknowledge the needs and competencies of the informal caregiver, to capacitate them in looking after their relatives, in order to help decrease their burden and consequently, decrease the number of hospital readmissions that may be related to the quality of care provided at home.

\section{Supplementary information}

Supplementary information accompanies this paper at https://doi.org/10. 1186/s12877-019-1274-0.

Additional file 1. Informal caregiver's skill assessment tool. (DOCX 50 kb)

\section{Abbreviations}

ADL: Activities Daily Living; IADL: Instrumental Activities of Daily Living; ICT: Information and communication technologies; rs: Spearman's correlation; U: Mann-Whitney test

\section{Acknowledgements}

The authors of this study would like to thank all the participants of the study for taking their time to complete the survey information.

\section{Authors' contributions}

All authors took part in the entire study and approved final manuscript. MD, $L T, T A, R F, T P$ and $A Q$ contributed to drafting, data interpretation, and study design. D was responsible for data analysis and interpretation. MD, TP and AQ contributed to conception and collected the data. LT and AQ critically reviewed, revised and supplemented the manuscript. All authors read and approved the final manuscript.

\section{Funding}

This work was supported by Portuguese project AAC in 02/SAICT/2016 reference number 023662/2016, is funded by the program COMPETE 2020 under the Scientific and Technological Research Support System, with an incentive of European Regional Development Fund (ERDF).

The funder had no role in the study design, data collection, data analysis, interpretation of data, presentation of results, or decision to submit for publication

\section{Availability of data and materials}

The datasets used and/or analyzed during the current study are available from the corresponding author on reasonable request.

\section{Ethics approval and consent to participate}

The study has been approved by the Research Ethics Committee at Central Hospital of Leiria Ethics Committee (04-2017/05/02).

Participants have been informed of the research objectives and have given their written consent. Their anonymity has been guaranteed.

\section{Consent for publication}

Not applicable.

\section{Competing interests}

The authors declare that they have no competing interests.

\section{Author details}

${ }^{1}$ Center for Innovative Care and Health Technology, Escola Superior de Saúde do instituto Politécnico de Leiria, Campus 2 - Morro do Lena, Alto do Vieiro - Apartado 4137, 2411-901 Leiria, Portugal. Escola Superior de Saúde do instituto Politécnico de Leiria, Campus 2 - Morro do Lena, Alto do Vieiro Apartado 4137, 2411-901 Leiria, Portugal. ${ }^{3}$ Centro Hospitalar de Leiria, Rua das Olhalvas, 2410-197 Leiria, Portugal.

Received: 8 June 2019 Accepted: 10 September 2019

Published online: 18 September 2019

\section{References}

1. United Nations. World population ageing. New York; 2017. http://www.un. org/en/development/desa/population/publications/pdf/ageing/WPA2017_ Report.pdf

2. United Nations Department of Economic and Social Affairs Population Division. World population prospects the 2017 revision key findings and advance tables. New York: working paper no. ESA/P/WP/248. Cover; 2017. https://esa.un.org/unpd/wpp/Publications/Files/WPP2017_KeyFindings.pdf.

3. Mathers CD, Stevens GA, Boerma T, White RA, Tobias MI. Causes of international increases in older age life expectancy. Lancet. 2015;385:540-8. https://doi.org/10.1016/S0140-6736(14)60569-9.

4. Marques R, Dixe M, Querido A, Sousa P. Revalidation of the holistic comfort questionnaire - family for caregivers of people with advanced chronic disease. Rev Enferm Ref. 2016;IV Série:91-100. https://doi.org/10.12707/ RIV16060.

5. Hajek A, König HH. Informal caregiving and subjective well-being: evidence of a population-based longitudinal study of older adults in Germany. J Am Med Dir Assoc. 2016;17:300-5.

6. Rafnsson SB, Shankar A, Steptoe A. Informal caregiving transitions, subjective well-being and depressed mood: findings from the English longitudinal study of ageing. Aging Ment Health. 2017;21:104-12. https:// doi.org/10.1080/13607863.2015.1088510.

7. Family Caregiver Alliance ${ }^{\circledast}$ - National Center on Caregiving. Definitions. 2014. https://www.caregiver.org/definitions-0.

8. Reinhard S, Levine C, Samis S. Home alone: family caregivers providing complex chronic care. Washington: AARP Public Policy Institute; 2012.

9. Paterson DA, Burgess MJ. Sustaining informal caregivers. New York; 2009.

10. Rosell-Murphy M, Bonet-Simo JM, Baena E, Prieto G, Bellerino E, Solé F, et al. Intervention to improve social and family support for caregivers of ndependent patients: ICIAS study protocol. BMC Fam Pract. 2014;15:53. https://doi.org/10.1186/1471-2296-15-53.

11. Grant JS, Graven LJ. Problems experienced by informal caregivers of individuals with heart failure: an integrative review. Int J Nurs Stud. 2018;80 November 2017:41-66. https://doi.org/10.1016/j.jjnurstu.2017.12.016.

12. Orem D. Nursing: concepts of practice. ( $6^{\mathrm{a}}$ ed). St. Louis: Mosby; 2001.

13. Rotondi A;J, Sinkule J, Balzer K, Harris J, Moldovan R. A qualitative needs assessment of persons who have experienced traumatic brain injury and their primary family caregivers. J Head Trauma Rehabil. 2007; 22:14-25

14. Rabow MW, Hauser JM, Adams J, Rabow MW, Hauser JM, Adams J. Supporting family caregivers at the end of life: "they don't know what they don't know". JAMA J Am Med Assoc 2004;291:483-491. http://sire.ub.edu/ login?url=http://search.ebscohost.com/login.aspx?direct=true \&db=ccm\&AN= 106758368\&login.asp\&lang=es\&site=ehost-live\&scope=site.

15. Rodríguez-Sánchez E, Pérez-Peñaranda A, Losada-Baltar A, PérezArechaederra D, Gómez-Marcos MÁ, Patino-Alonso MC, et al. Relationships between quality of life and family function in caregiver. BMC Fam Pract. 2011;12:19. https://doi.org/10.1186/1471-2296-12-19.

16. Martins T, Ribeiro JP, Garret C. Estudo de validação do questionário de avaliação da sobrecarga para cuidadores informais. Psicol Saúde Doenças. 2003:4:131-48.

17. Burman ME. Family caregiver expectations and management of the stroke trajectory. Rehabil Nurs. 2001;26:94-8.

18. Oldenkamp M, Bültmann U, Wittek RPM, Stolk RP, Hagedoorn M, Smidt N. Combining informal care and paid work: the use of work arrangements by working adult-child caregivers in the Netherlands. Heal Soc Care Community. 2018;26:e122-31.

19. Pinquart M, Sörensen S. Spouses, adult children, and children-in-law as caregivers of older adults: a meta-analytic comparison. Psychol Aging. 2011;26:1-14. 
20. Litzelman K, Green PA, Yabroff KR. Cancer and quality of life in spousal dyads: spillover in couples with and without cancer related health problems. Support Care Cancer. 2016;24:763-71.

21. Hajek A, König HH. The role of flexible goal adjustment in the effect of informal caregiving on depressive symptoms: evidence of a large population-based longitudinal study in Germany from 2002 to 2011. Qual Life Res. 2017;26:419-27.

22. Smith GR, Williamson GM, Miller LS, Schulz R. Depression and quality of informal care: a longitudinal investigation of caregiving stressors. Psychol Aging. 2011;26:584-91.

23. Tan J-Y, Molassiotis A, Lloyd-Williams M, Yorke J. Burden, emotional distress and quality of life among informal caregivers of lung cancer patients: an exploratory study. Eur J Cancer Care (Engl). 2017; March:e12691. https://doi. org/10.1111/ecc.12691

24. Deshields TL, Rihanek A, Potter P, Zhang Q, Kuhrik M, Kuhrik N, et al. Psychosocial aspects of caregiving: perceptions of cancer patients and family caregivers. Support Care Cancer. 2012;20:349-56.

25. Fletcher BS, Paul SM, Dodd MJ, Schumacher K, West C, Cooper B, et al. Prevalence, severity, and impact of symptoms on female family caregivers of patients at the initiation of radiation therapy for prostate cancer. J Clin Oncol. 2008;26:599-605.

26. Rha SY, Park Y, Song SK, Lee CE, Lee J. Caregiving burden and the quality of life of family caregivers of cancer patients: the relationship and correlates. Eur J Oncol Nurs. 2015;19:376-82. https://doi.org/10.1016/.jejon.2015.01.004.

27. Fujinami R. Family caregivers distress levels related to quality of life burden, and preparedness. Psychooncology. 2015;24:54-62

28. Shyu Y-I. The needs of family caregivers of frail elders during the transition from hospital to home: a taiwanese sample. J Adv Nurs. 2000;32(3):619-25.

29. Romaniello C, Simoni C, Farinelli M, Bertoletti E, Pedone V, Northoff G. Emotional burden, quality of life, and coping styles in care givers of patients with disorders of consciousness living in Italy: preliminary data. Brain Impair. 2016;17:254-64.

30. Floriano LA, Azevodo RCS, Reiners AAO, Sudré MRS. Care performed by family caregivers to dependent elderly, at home, within the context of the family health strategy. Text Context Nursing, Florianópolis, 2012 Jul-Sep; 21(3): 543-548.

31. Yuda M, Lee J. Effects of informal Caregivers' health on care recipients. Jpn Econ Rev. 2016;67(2):192-210

32. Costa SRD, Castro EAB. Self-care in family caregiver of dependent adults or elderly persons after hospital discharge. Rev Bras Enferm. 2014 nov-dez; 67(6):979-86.

33. RightTimePlaceCare Consortium, Hamers, J, Beerens, H, Bleijlevens, M, Zwakhalen, S, Ruwaard, D \& Ambergen, A 2016, What Makes Institutional Long-Term Care the Most Appropriate Setting for People With Dementia? Exploring the Influence of Client Characteristics, Decision-Maker Attributes, and Country in 8 European Nations' Journal of the American Medical Directors Association, vol. 17, no. 5, pp. 465.e9-465.e15. DOl: 10.1016/j.jamda.2016.02.025.

34. Parry C, Mahoney E, Chalmers SA, Coleman EA. Assessing the quality of transitional care further applications of the care transitions measure. Med Care. 2008:46(3):317-22.

35. Lotus Shyu YI, Chen MC, Lee HC. Caregiver's needs as predictors of hospital readmission for the elderly in Taiwan. Soc Sci Med. 2004;58(7):1395-403. https://doi.org/10.1016/50277-9536(03)00334-4.

\section{Publisher's Note}

Springer Nature remains neutral with regard to jurisdictional claims in published maps and institutional affiliations.

\section{Ready to submit your research? Choose BMC and benefit from:}

- fast, convenient online submission

- thorough peer review by experienced researchers in your field

- rapid publication on acceptance

- support for research data, including large and complex data types

- gold Open Access which fosters wider collaboration and increased citations

- maximum visibility for your research: over $100 \mathrm{M}$ website views per year

At $\mathrm{BMC}$, research is always in progress.

Learn more biomedcentral.com/submissions 